\title{
Decline in head growth and cognitive impairment in survivors of acute lymphoblastic leukaemia
}

\author{
R E Appleton, K Farrell, J Zaide, P Rogers
}

\begin{abstract}
Twenty five children in remission, who were asymptomatic and who had last been treated at least two years before for acute lymphoblastic leukaemia, were examined neurologically and neuropsychologically. Their treatment included early cranial irradiation ( $24 \mathrm{~Gy}$ or $18 \mathrm{~Gy}$ ), intrathecal methotrexate, and systemic chemotherapy. One half of the children demonstrated a decline in head circumference centile, which occurred in all patients treated with $24 \mathrm{~Gy}$ and in those patients treated with $18 \mathrm{~Gy}$ under the age of 3 years. In those children whose head growth was reduced, performance was significantly impaired in neuropsychological tests designed to assess concentration and short term memory. These children also developed clinically important learning difficulties in the classroom. Minor neurological dysfunction was present in almost half of the entire group. These data suggest that the treatment employed to prevent central nervous system leukaemia (primarily cranial irradiation) has a deleterious effect on head and brain growth and intellectual function.
\end{abstract}

The current use of combination chemotherapy and central nervous system directed treatment has resulted in prolonged disease free survival in most children with acute lymphoblastic leukaemia. ${ }^{1}$ This survival may be associated with neuropsychological complications, however, which have been attributed primarily to the use of cranial irradiation. ${ }^{2-4}$

Previous studies have focused on the neuropsychological state of asymptomatic childhood survivors of acute lymphoblastic leukaemia, because of concern over learning difficulties and consequent school delay. ${ }^{2-5}$ There is little information on the neurological findings of these children with respect to the prevalence of 'soft' neurological signs and, in particular, patterns of head and, presumably, brain growth.

The purpose of this paper is to present the patterns of head growth and neurological and neuropsychological findings in 25 children, who were disease free and who were studied at least two years after the cessation of treatment for acute lymphoblastic leukaemia. The study has employed a number of psychological tests, some of which have not been used previously in the assessment of children treated for acute lymphoblastic leukaemia, and which can be administered during a routine medical clinical visit.

Department of Oncology P Rogers

Correspondence to: Dr R E Appleton, Children's Department, Newcastle General Hospital, Westgate Road, Newcastle upon Tyne NE4 6BE.

Accepted 26 January 1990

\section{Patients and methods}

PATIENTS

Twenty five children who were in remission, and who had last been treated at least two years before for acute lymphoblastic leukaemia, underwent neurological and neuropsychological evaluation. Countries of origin included Canada/North America (19 patients) and two patients from each of Sweden, Portugal, and India. The patients' ages at diagnosis ranged from $1.4-8.8$ (mean 3.5 ) years and at examination, from $7 \cdot 0-18.5$ (mean 11.0 ) years. The children had been off treatment for between two and 12 (mean four) years at the time of evaluation. All the children had been treated using the protocols established by the North America Children's Cancer Study Group according to the risk criteria and the appropriate protocol open at the time of diagnosis. Systemic induction chemotherapy consisted of crisantaspase (Lasparaginase), prednisone, vincristine, intrathecal methotrexate, and 6-mercaptopurine, followed by central nervous system directed treatment comprising cranial irradiation and intrathecal methotrexate or intrathecal methotrexate alone. Continuing (maintenance) chemotherapy comprised daily 6-mercaptopurine, weekly methotrexate, and monthly pulses of vincristine and prednisone and was administered for a total of either $24(n=9)$ or $36(n=16)$ months. Central nervous system directed treatment was given during the consolidation phase and comprised $24 \mathrm{~Gy}(\mathrm{n}=6)$ or $18 \mathrm{~Gy}(\mathrm{n}=13)$, delivered in either 2 or $1.8 \mathrm{~Gy} /$ day fractions. Six children did not receive cranial irradiation. All 25 patients received intrathecal methotrexate: in 12 patients this was confined to six, weekly injections $\left(12 \mathrm{mg} / \mathrm{m}^{2}\right)$, while in the remaining 13 patients, additional injections $\left(12 \mathrm{mg} / \mathrm{m}^{2}\right)$ were given at intervals of three months over a one, two, or three year period (tables 1 and 2). Cytocentrifuge analysis of the cerebrospinal fluid was performed in each patient at diagnosis, during, and after completion of treatment. Relapses occurred in three children (two boys), all of whom were off treatment; sites of relapse were testes (two) and bone marrow. Treatment of these relapses included an additional 12 months of 'maintenance' chemotherapy. None of the three patients who relapsed were given further cranial radiation. Growth hormone studies were not performed in any patient.

\section{Methods}

Neurological examination

Each patient was examined neurologically by the same author (REA). A specific assessment was made for the presence of minor or 'soft' neurological signs including motor immaturity (Fog test looking for associated abnormal movements ${ }^{6}$ ), problems with coordination (finger touching skills, rapid alternating movements of hands, hopping, foot tapping) and right/left confusion. ${ }^{7}$ The same author performed all measurements of the occipitofrontal head circumference using a steel 
Table 1 Demographic features of the 12 children who showed a change in head circumference centiles

\begin{tabular}{|c|c|c|c|c|c|c|c|c|}
\hline \multirow{2}{*}{$\begin{array}{l}\text { Case } \\
\text { No/Sex }\end{array}$} & \multicolumn{2}{|c|}{ Age (years) } & \multicolumn{2}{|c|}{$\begin{array}{l}\text { Occipitofrontal head } \\
\text { circumference centile }\end{array}$} & \multirow{2}{*}{$\begin{array}{l}\text { Radiotherapy } \\
(G y)\end{array}$} & \multirow{2}{*}{$\begin{array}{l}\text { Intrathecal } \\
\text { methotrexate } \\
\text { (mg/duration) }\end{array}$} & \multirow{2}{*}{$\begin{array}{l}\text { Result of } \\
\text { neurological } \\
\text { examination }\end{array}$} & \multirow{2}{*}{$\begin{array}{l}\text { School } \\
\text { delay }\end{array}$} \\
\hline & Diagnosis & Assessment & Diagnosis & Assessment & & & & \\
\hline$\frac{1 / F}{2 / F}$ & $\begin{array}{l}1 \cdot 5 \\
1.8\end{array}$ & $\begin{array}{r}17 \cdot 3 \\
9 \cdot 9\end{array}$ & $\begin{array}{l}50 \\
60\end{array}$ & $\begin{array}{l}2 \\
2\end{array}$ & $\begin{array}{l}24 \\
18\end{array}$ & $\begin{array}{l}100 / 3 \text { years } \\
72 / 6 \text { weeks }\end{array}$ & $\begin{array}{l}\text { Normal } \\
\text { Poor coordination, } \\
\text { positive Fog }\end{array}$ & Maths \\
\hline $3 / F$ & $2 \cdot 2$ & $12 \cdot 8$ & 60 & 10 & 24 & $36 / 1$ year & $\begin{array}{l}\text { Sensorineural } \\
\text { deafness, poor } \\
\text { right/left } \\
\text { discrimination }\end{array}$ & 1 year \\
\hline $4 / \mathrm{F}^{*}$ & $2 \cdot 5$ & $7 \cdot 6$ & 60 & 25 & 18 & $140 / 2$ years & $\begin{array}{l}\text { Poor coordination, } \\
\text { positive Fog, } \\
\text { poor right/left } \\
\text { discrimination }\end{array}$ & 1 year \\
\hline $\begin{array}{l}5 / F \\
6 / M^{*}\end{array}$ & $\begin{array}{l}3 \cdot 2 \\
1 \cdot 5\end{array}$ & $\begin{array}{l}14 \cdot 2 \\
10 \cdot 5\end{array}$ & $\begin{array}{l}60 \\
75\end{array}$ & $\begin{array}{l}25 \\
25\end{array}$ & $\begin{array}{l}24 \\
18\end{array}$ & $\begin{array}{l}35 / 6 \text { weeks } \\
36 / 6 \text { weeks } \\
100 / 2 \text { years }\end{array}$ & $\begin{array}{l}\text { Hyperreflexia } \\
\text { Flaccid paraplegia }\end{array}$ & $\begin{array}{l}\text { No } \\
1 \text { year }\end{array}$ \\
\hline $\begin{array}{c}7 / M \\
8 / M \\
9 / M \\
10 / M \\
11 / M \\
12 / M^{*}\end{array}$ & $\begin{array}{l}1 \cdot 7 \\
2 \cdot 1 \\
3 \cdot 0 \\
4 \cdot 0 \\
6 \cdot 5 \\
6 \cdot 5\end{array}$ & $\begin{array}{r}13 \cdot 4 \\
9 \cdot 0 \\
16 \cdot 0 \\
14 \cdot 5 \\
15 \cdot 0 \\
18 \cdot 5\end{array}$ & $\begin{array}{l}60 \\
60 \\
25 \\
40 \\
50 \\
60\end{array}$ & $\begin{array}{l}25 \\
10 \\
<2 \\
10 \\
10 \\
10\end{array}$ & $\begin{array}{l}24 \\
18 \\
18 \\
24 \\
18 \\
24\end{array}$ & $\begin{array}{l}36 / 6 \text { weeks } \\
60 / 6 \text { weeks } \\
72 / 6 \text { weeks } \\
48 / 6 \text { weeks } \\
156 / 2 \text { years } \\
220 / 2 \cdot 5 \text { years }\end{array}$ & $\begin{array}{l}\text { Hyperreflexia } \\
\text { Normal } \\
\text { Hyperreflexia } \\
\text { Normal } \\
\text { Normal } \\
\text { Normal }\end{array}$ & $\begin{array}{l}1 \text { year } \\
1 \text { year } \\
1 \text { year } \\
\text { No } \\
\text { Maths } \\
1 \text { year }\end{array}$ \\
\hline
\end{tabular}

${ }^{*}$ Abnormal computed tomography of the head: cases 4 and 12-calcification of frontal lobes and basal ganglia; case 6 -calcification of frontal lobes and dilatation of the lateral ventricles and subarachnoid spaces.

Table 2 Demographic features of the 13 children whose head circumference centiles were unchanged

\begin{tabular}{|c|c|c|c|c|c|c|c|c|}
\hline \multirow{2}{*}{$\begin{array}{l}\text { Case } \\
\text { No/Sex }\end{array}$} & \multicolumn{2}{|c|}{ Age (years) } & \multicolumn{2}{|c|}{$\begin{array}{l}\text { Occipitofrontal head } \\
\text { circumference }\end{array}$} & \multirow{2}{*}{$\begin{array}{l}\text { Radiotherapy } \\
(G y)\end{array}$} & \multirow{2}{*}{$\begin{array}{l}\text { Intrathecal } \\
\text { methotrexate } \\
\text { (mg/duration) }\end{array}$} & \multirow{2}{*}{$\begin{array}{l}\text { Result of } \\
\text { neurological } \\
\text { examination }\end{array}$} & \multirow{2}{*}{$\begin{array}{l}\text { School } \\
\text { delay }\end{array}$} \\
\hline & Diagnosis & Assessment & Diagnosis & Assessment & & & & \\
\hline $\begin{array}{l}1 / F \\
2 / F \\
3 / F \\
4 / F \\
5 / F\end{array}$ & $\begin{array}{l}2 \cdot 0 \\
2 \cdot 5 \\
3 \cdot 5 \\
3 \cdot 8 \\
4 \cdot 0\end{array}$ & $\begin{array}{r}7 \cdot 0 \\
7 \cdot 5 \\
11 \cdot 5 \\
10 \cdot 5 \\
11 \cdot 0\end{array}$ & $\begin{array}{l}25 \\
25 \\
25 \\
75 \\
60\end{array}$ & $\begin{array}{l}25 \\
25 \\
25 \\
75 \\
60\end{array}$ & $\begin{array}{r}0 \\
0 \\
18 \\
18 \\
0\end{array}$ & $\begin{array}{c}152 / 2 \text { years } \\
92 / 2 \text { years } \\
72 / 1 \text { year } \\
72 / 6 \text { weeks } \\
108 / 2 \text { years }\end{array}$ & $\begin{array}{l}\text { Normal } \\
\text { Normal } \\
\text { Positive Fog test } \\
\text { Normal } \\
\text { Unilateral } \\
\quad \text { sensorineural } \\
\text { deafness }\end{array}$ & $\begin{array}{l}\text { No } \\
\text { No } \\
\text { No } \\
\text { No } \\
1 \text { year }\end{array}$ \\
\hline $6 / F$ & $4 \cdot 3$ & $8 \cdot 5$ & 60 & 60 & 0 & $216 / 2$ years & $\begin{array}{l}\text { Unilateral } \\
\text { sensorineural } \\
\text { deafness }\end{array}$ & No \\
\hline $\begin{array}{l}7 / F \\
8 / F \\
9 / M\end{array}$ & $\begin{array}{l}5 \cdot 1 \\
5 \cdot 9 \\
1 \cdot 6\end{array}$ & $\begin{array}{r}9 \cdot 2 \\
11 \cdot 5 \\
7 \cdot 0\end{array}$ & $\begin{array}{l}75 \\
90 \\
50\end{array}$ & $\begin{array}{l}75 \\
90 \\
50\end{array}$ & $\begin{array}{r}18 \\
0 \\
0\end{array}$ & $\begin{array}{r}60 / 2 \text { years } \\
168 / 2 \text { years } \\
82 / 2 \text { years }\end{array}$ & $\begin{array}{l}\text { Positive Fog test } \\
\text { Positive Fog test } \\
\text { Poor left/right } \\
\text { discrimination }\end{array}$ & $\begin{array}{l}\text { Maths } \\
\text { No } \\
\text { No }\end{array}$ \\
\hline $\begin{array}{l}10 / M \\
11 / M \\
12 / M \\
13 / M\end{array}$ & $\begin{array}{l}4 \cdot 6 \\
4 \cdot 8 \\
5 \cdot 2 \\
8 \cdot 8\end{array}$ & $\begin{array}{l}10 \cdot 2 \\
10 \cdot 5 \\
10 \cdot 5 \\
14 \cdot 5\end{array}$ & $\begin{array}{l}25 \\
60 \\
90 \\
75\end{array}$ & $\begin{array}{l}25 \\
60 \\
90 \\
75\end{array}$ & $\begin{array}{l}18 \\
18 \\
18 \\
18\end{array}$ & $\begin{array}{l}72 / 6 \text { weeks } \\
72 / 6 \text { weeks } \\
72 / 6 \text { weeks } \\
72 / 6 \text { weeks }\end{array}$ & $\begin{array}{l}\text { Positive Fog test } \\
\text { Normal } \\
\text { Normal } \\
\text { Absent deep } \\
\text { tendon reflexes }\end{array}$ & $\begin{array}{l}\text { No } \\
1 \text { year } \\
\text { No } \\
\text { No }\end{array}$ \\
\hline
\end{tabular}

tape measure. Head circumference centiles were derived from composite international and interracial data (birth to 18 years) prepared by Nelhaus. ${ }^{8}$

\section{Neuropsychological tests}

A neuropsychological battery was developed using two criteria: firstly the battery should comprise tests known to be sensitive to disturbance of specific functions of the brain (particularly concentration and memory), and secondly, the tests should be able to be administered within a short time (20 minutes) by a non-psychologist. The following six tests were employed: performance on the Purdue Pegboard to assess dexterity, speed, and hand coordination ${ }^{9}{ }^{10}$; sentence repetition and word fluency to assess memory, verbal spontaneity, and language function ${ }^{11}$; recognition of embedded figures to assess visual attention and perception ${ }^{12}$; and coding and digit span (two subtests from the Wechsler intelligence scales for children-revised $^{13}$ ) to assess visual memory and short term memory, and concentration respectively. Because of the practical difficulties in identifying a suitable group of children, including siblings, controls were not used. However, for each of the six tests there are normative data ('normal populations') which are sex and age related. For embedded figures, 'norms' are only available for children aged 14 years or less. The tests were administered in accordance with standardised procedures, by one author (REA) at the same time as the neurologic examination.

\section{School delay}

Reports from the patient's schools were available on each child.

\section{Computed tomography}

Computed tomography of the head, using a GECT 8800 scanner, was performed on 13 children between $5 \cdot 1$ and 14.8 (mean $8 \cdot 1$ ) years from diagnosis, at the time of the neurological evaluation. Interpretation was undertaken by a neuroradiologist who was blinded to the clinical information of the patients.

\section{Statistical analysis}

Head circumference measurements and performances on the neuropsychological tests in the 25 children were analysed using the two sample $t$ test. Head circumference measurements and school delay was analysed using the $\chi^{2}$ test, with Yates's correction. 
Results

The birth weights were appropriate for gestational age and the perinatal periods and early development were reported to have been normal in all 25 children. No patient developed meningeal leukaemia or clinical or laboratory evidence of thyroid dysfunction.

Paired measurements of occipitofrontal head circumference at diagnosis and at follow up were available in all 25 children. There was a bimodal distribution of occipitofrontal head circumference centile measurements with either no change in occipitofrontal head circumference centile $(n=13)$ or an obvious decline $(n=12)$ of between $30 \%$ and $57 \%$ (tables 1 and 2 ). In only one child did the head circumference fall below the second centile (case 9, table 1). All six children who had received a dosage of $24 \mathrm{~Gy}$ demonstrated a decrease in centiles (mean time from diagnosis 12 years). Only six of 13 children who had received a dose of $18 \mathrm{~Gy}$ showed a decrease in centiles (mean time from diagnosis 8.5 years); five of these six had been diagnosed and had received cranial irradiation under the age of 3 years. The mean declines in head circumference centile were the same in those children treated with either $18 \mathrm{~Gy}$ or $24 \mathrm{~Gy}$. The remaining seven children who had received $18 \mathrm{~Gy}$ and who did not show a decline in head circumference centile had all been diagnosed over the age of 3 years (mean time from diagnosis 6.0 years) Head circumference centiles were unchanged in the six children who did not receive crania irradiation (mean time from diagnosis 5.4 years).

The demographic data, details of central nervous system directed treatment employed, results of neurological findings, and frequency of school delay in the 25 children who did and did not demonstrate a change in head circumference centiles are described in tables 1 and 2 respectively. The standardised, mean scores achieved in the neuropsychological tests and the significance of difference in the means in the two groups are shown in table 3.

Thirteen of the 25 children had clinically important learning difficulties, of whom 10 were at least one year behind at school; eight of these 10 had a reduction in head growth. A further three children (two showing a decline in head circumference) had a more specific learning difficulty with mathematics which necessitated placement in a remedial class for this subject.

Major neurological complications were seen in only one child (table 1 , case 6 ) who developed a flaccid paraplegia after Coxsackie transverse myelitis before the use of chemotherapy. This boy subsequently developed seizures associated with fever during treatment; no other patient in this series developed seizures. Three girls developed unilateral sensorineural deafness, one of whom also demonstrated minor neurological abnormalities, but it was not possible to determine whether this was due to a leukaemic infiltrate, effect of chemotherapy or the result of infection. Computed tomography of the head, analysis of the cerebrospinal fluid, and viral studies were normal or negative in these patients. Twelve children had evidence of minor neurological dysfunction indicated by motor immaturity, problems with coordination or right/left discrimination (or both), or with abnormalities of muscle tone or deep tendon reflexes.

Three of the 13 children investigated with computed tomography of the head had abnormal findings (table 1). All three performed badly on the sentence repetition, digit span, and word fluency tests.

\section{STATISTICAL ANALYSIS}

(1) Declines in head circumference centiles were analysed in respect of the following variables:

(a) Age at diagnosis-In children treated with $24 \mathrm{~Gy}$, age at diagnosis did not appear to be a significant variable. In children treated with 18 $\mathrm{Gy}$, declines in head growth were significantly more common if the age at diagnosis was 3 years or less $(\mathrm{p}=0.038)$.

(b) Dosage of cranial radiation-There was no significant difference in the amount of decline between patients treated with either $24 \mathrm{~Gy}$ or $18 \mathrm{~Gy}$.

(c) Neuropsychological performance-In those children who had a change in head circumference centile, compared with those children whose centiles were unchanged, performance was significantly impaired in sentence repetition $(p=0.007)$ and digit span $(p=0.02)$; word fluency just failed to reach statistical signifi-

Table 3 School delay, neurological abnormalities, mean scores in neuropsychological tests, and their significance of difference in the children who did and did not show a change in head circumference centiles. Results are mean $(S D)$ unless stated otherwise

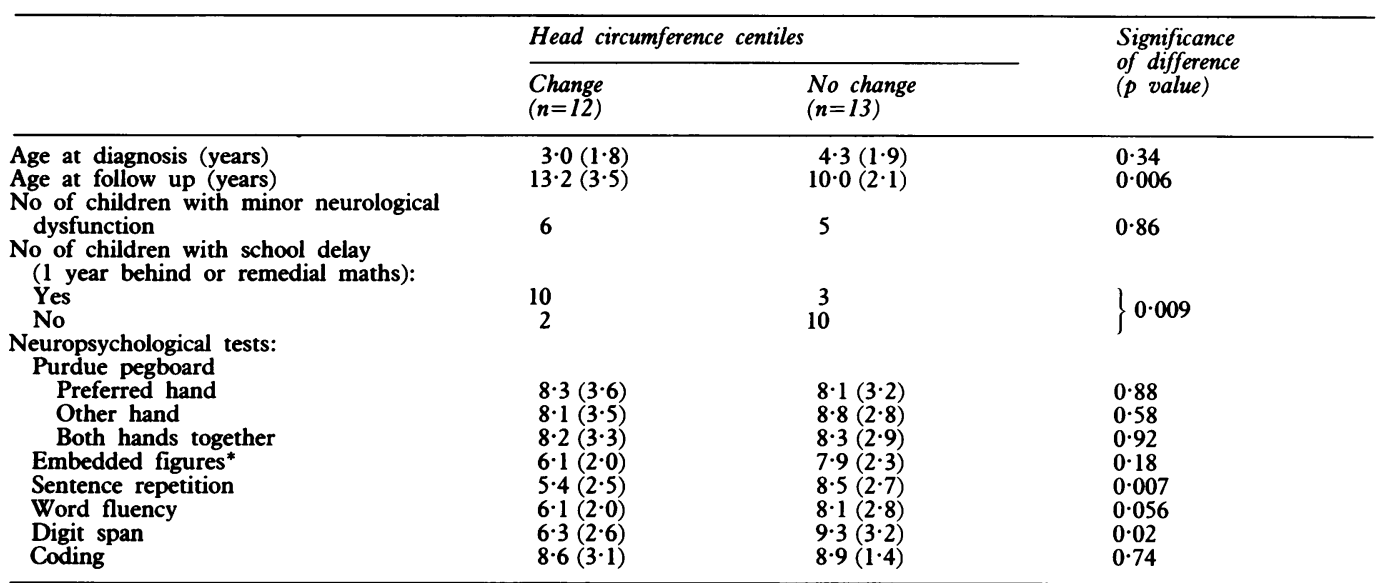

*For embedded figures the comparison is between six children who did and the 12 children who did not show a change in head circumference centile (see text: neuropsychological tests in methods). 
cance $(p=0.056)$ (table 3$)$. When the children who had a decline in head circumference centile were compared with a normal population, however, performance was significantly impaired in sentence repetition $(p=0.0006)$, digit span $(p=0.006)$, word fluency $(p=0.003)$, and embedded figures $(\mathrm{p}=0.003)$.

(d) School delay-Learning difficulties (remedial maths or one year behind) occurred more frequently in those children who had a decline in head growth $(p=0.009)$.

(2) Performances in each of the six neuropsychological tests in a normal population (derived from the normative data) were compared with performances in: (a) the entire study group of 25 children, and (b) the 13 children who did not show a decline in head circumference centiles. No significant differences were found in any of the tests.

Regression analysis revealed that neither parental education nor socioeconomic status accounted for any of the cognitive variability (neuropsychological performance or school delay) seen in the children.

\section{Discussion}

In this study we have shown that a reduction in the pattern of head growth seems to relate closely to neuropsychological difficulties and school delay among childhood survivors of acute lymphoblastic leukaemia. Almost half of the children in this series had a decrease in head circumference centile. A reduction occurred in all six children who received a radiation dose of $24 \mathrm{~Gy}$, irrespective of age at diagnosis. In contrast, a reduction occurred in less than half of those children who received a dose of $18 \mathrm{~Gy}$ and, in those children whose head circumference centiles were unchanged, all were over 3 years of age at diagnosis. The dosages and durations of administration of intrathecal methotrexate were similar in the two groups of children. Thus intrathecal methotrexate did not appear to be a significant factor in the decline in head growth. However, a contributory effect of the drug cannot be excluded. Although the mean period of follow up was slightly shorter in the patients treated with $18 \mathrm{~Gy}$ who did not demonstrate a change in head circumference centile (compared with the follow up period in those that did), it is unlikely that this was significant. The mean age at follow up was significantly older in the group of children whose head circumference changed; however, we do not feel that this altered significantly any of the results with respect to either the number of children with reduced head growth; or incidence of school delay, or performance on neuropsychological testing. Head circumference centiles were unchanged in the six children who did not receive cranial irradiation, of whom three were diagnosed and received intrathecal methotrexate before their third birthday. Despite the small number of patients in this study, these observations suggest that in the treatment of acute lymphoblastic leukaemia the greatest risk of affecting head and presumably brain growth is associated with cranial irradiation administered under the age of 3 years. As far as we are aware, this association has been reported only once previously, in abstract form. In the study by Urion et al all the children had received $24 \mathrm{~Gy}$ cranial irradiation and combination chemotherapy, of whom half had microcephaly (defined by an occipitofrontal head circumference less than the second centile). ${ }^{14}$ Cognitive function, as assessed by the Wechsler intelligence scale of children-revised, was impaired in many of these children, and this was in part related to age at diagnosis. Although only one patient in our series developed microcephaly (head circumference below the second centile), it is possible that this number would have been greater if the patients had been followed up for longer. Whether this would have been associated with a progressive decline in intellectual function is not clear but is unlikely. ${ }^{15}$ The frequency of cognitive impairment in our patients was similar to that of the study by Urion $e t a l .{ }^{14}$ This suggests that the critical factor may be a decline in head growth per se, rather than the amount of decline and eventual head circumference (including microcephaly).

In our study, there were significant correlations between decline in head growth, school delay, and impaired performance on neuropsychological testing, particularly in those tests involving concentration and immediate or short term memory. There were also correlations between a reduction in head growth and poor verbal spontaneity (measured by word fluency) and visual perception problems (assessed by embedded figures). However, children whose head growth was unchanged performed no worse than a normal population.

Previous studies have also emphasised the findings of poor concentration and memory deficits in childhood survivors of acute lymphoblastic leukaemia. ${ }^{5} 1617$ This suggests that it is the impairment of these specific abilities which are primarily responsible for cognitive dysfunction and consequent school delay. The acquisition of knowledge relies heavily on attention and memory skills. Learning difficulties and consequently school delay are more likely to result from a slowing in the rate of acquisition of new skills and information in which concentration and memory problems play a central part, rather than by an actual loss of previously acquired knowledge.

A possible neuropathological substrate for both the reduction in head growth and impairment of memory is a disturbance of brain myelination consequent to cranial irradiation. ${ }^{18} 19$ Myelination of the central nervous system commences in utero but is not complete until the second or third year of life. ${ }^{20}$ This could explain the frequently reported observations, including our own, that those children at greatest risk from developing (or who actually have) reduced head growth, memory impairment, and consequent school delay, are aged 3 years or less at diagnosis. ${ }^{2} 162122$ As skills accrue with age, the abilities of younger children who have been given central nervous system directed treatment could be arrested at more elementary levels because of early disruption in brain development. This could also result in relative immaturity of the motor system, manifest by the presence of associated movements on the Fog test or as difficulties with fine motor coordination, visual perceptual problems, and right/ left confusion-so called 'soft' neurological signs. Almost one half of the children in our series had evidence of minor neurological dysfunction, particularly problems with associated movements, coordination, right/left discrimination, and abnormalities of muscle tone. Such abnormalities are commonly seen in children with 'minimal cerebral dysfunction', ${ }^{7}$ and it is perhaps not unexpected that the additional clinical hallmarks 
of this disorder include short attention span, increased distractability, and poor memory function. These characteristics and a lack of verbal spontaneity are frequently associated with lesions of the frontal lobe ${ }^{23}$; calcification and atrophy of the frontal lobes were seen in three of our patients and have been described in other asymptomatic survivors of acute lymphoblastic leukaemia. ${ }^{24}$ Although 'soft' neurological signs may be underrecognised and their presence or significance disputed, very few studies have specifically looked for them in asymptomatic survivors of childhood acute lymphoblastic leukaemia.

The rate of head growth may be subnormal in malnourished children ${ }^{25}$ but accelerates rapidly with proper nutrition. ${ }^{26}$ None of our patients had clinically important weight loss during treatment and all were thriving at the time of the study. Similarly, no child had permanent hair loss as a result of treatment, which could have influenced head size. It is unlikely therefore that the 30 to $57 \%$ reduction in head circumference centiles seen in our children was due to a nutritional or non-specific response to acute lymphoblastic leukaemia. Although observer error cannot be excluded, it is also unlikely that errors in measurement were responsible. The reduction more probably reflects a direct effect of cranial irradiation, either alone or in combination with chemotherapy.

Finally, the differing methods and conflicting findings of at least 28 outcome studies of acute lymphoblastic leukaemia have caused considerable confusion over the neuropsychological effects of central nervous system directed treatment. ${ }^{27}$ Our findings suggest that among childhood survivors of acute lymphoblastic leukaemia, it may only be those children who show a reduction in head growth who develop neuropsychological complications. Further studies which specifically examine the association between the patterns of head growth and cognitive function in these children may help to resolve some of this confusion.

Although this study is small and retrospective, our findings suggest that central nervous system directed treatment (predominantly cranial irradition) has a significant adverse effect on head (and presumably brain) growth and cognitive development that is in part related to age.

We are grateful to Dr Peter Kelly for his assistance in the statistical analysis and to Mrs Sue Faulker for her help in the preparation of this manuscript.

1 Poplack DG. Acute lymphoblastic leukaemia in childhood. Pediatr Clin North Am 1985;32:669-97.

2 Meadows AT, Massari DJ, Fergusson J, Gordon J, Littman P, Moss K. Declines in IQ scores and cognitive dysfunctions $\mathrm{P}$, Moss K. Declines in IQ scores and cognitive dysfunctions
in children with acute lymphoblastic leukaemia with cranial in children with acute lymphoblastic
irradiation. Lancet $1981 ; \mathrm{ii}: 1015-8$.
3 Moss HA, Nannis ED, Poplack DG. The effects of prophylactic treatment of the central nervous system on the
intellectual functioning of children with acute lymphocytic intellectual functioning of children with
leukemia. Am $\mathcal{f}$ Med 1981;71:47-52.

leukemia. Am $\mathcal{F}$ Med 1981;71:47-52.
4 Pfefferbaum-Levine B, Copeland DR, Fletcher JM, Ried HL, Jaffe N, McKinnon WR. Neuropsychologic assessHL, Jaffe N, McKinnon WR. Neuropsychologic assess-
ment of long-term survivors of childhood leukemia. Am $\mathcal{J}$ ment of long-term survivors of childh
Pediatr Hematol Oncol 1984;6:123-8.

5 Goff JR, Anderson HR, Cooper PF. Distractability and memory deficits in long-term survivors of acute lymphoblastic leukaemia. 7 Dev Behav Pediatr 1980;1:158-63.

6 Fog E, Fog M. Cerebral inhibition examined by associated movements. In: Bax M, MacKeith R, eds. Minimal cerebral dysfunction. Little club clinics in Developmental Medicine and Child Neurology. No 10. London: Spastics Societey and Heinemann, 1963.

7 Touwen BCL. Examination of the child with minor neurological dysfunction. Clinics in developmental medicine. No 71 . London: Spastics International Medical Publications, 1979.

8 Nelhaus G. Head circumference from birth to eighteen years. Practical composite international and interracial graphs. Pediatrics 1968;41:106-14.

9 Rapin I, Tourk LM, Costa LD. Evaluation of the Purdue Pegboard as a screening test for brain damage. Dev Med Child Neurol 1966;8:45-54.

10 Costa LD, Vaughan HG Jr, Levita H, Farber N. Purdue pegboard as a predictor of the presence and laterality of cerebral lesions. Foumal of Consulting Psychology 1963;27: 133-7.

11 Spreen $\mathrm{O}$, Benton AL. Neurosensory center comprehensive examination for aphasia. Victoria, British Columbia, Canada: Department of Psychology, University of Victoria, 1977.

12 Spreen O, Gaddes WH. Developmental norms for 15 neuropsychological tests age 6 to 15. Cortex 1969;5:171-91.

13 Wechsler D. Manual for the Wechsler intelligence scale for children-revised. New York: The Psychological Corporation, 1974.

14 Urion DK, Waber D, Sallan S, Sollee N. Microcephaly and impaired cognitive function among survivors of acute lymphoblastic leukaemia who received prophylactic irradialymphoblastic leukaemia who rece
tion. Ann Neurol 1987;22:448.

15 Twaddle V, Britton PG, Kernahan J, Craft AW. Intellect after malignancy. Arch Dis Child 1986;61:700-2.

16 Brouwers P, Riccardi R, Poplack D, Fedio P. Attentional deficits in long-term survivors of childhood acute lymphoblastic leukaemia (ALL). Fournal of Clinical Neuropsychology 1984;6:325-36.

17 Mulhern RK, Wasserman AL, Fairclough D, Ochs J. Memory function in disease-free survivors of childhood acute lymphoblastic leukemia given CNS prophylaxis with or without 1,800 cGys cranial irradiation. $\mathcal{f}$ Clin Oncol 1988;6:315-20.

18 Dobbing J, Hopewell JW, Lynch A, Sands J. Vulnerability of developing brain: 1 . Some lasting effects of X-irradiation. Exp Neurol 1970;28:442-9.

19 Price R, Jamieson P. The central nervous system in childhood leukemia II. Subacute leukoencephalopathy. Cancer 1975;35:306-18.

20 Gilles FH, Shankle W, Dooling EC. Myelinated tracts: growth patterns. In: Gilles FH, Leviton A, Dooling EC, growth patterns. In: Gilles FH, Leviton A, Dooling EC, eds. The developing human brain: growth and epidem

21 Jannoun $\mathrm{L}$. Are cognitive and educational development affected by age at which prophylactic therapy is given in acute lymphoblastic leukaemia? Arch Dis Child 1983;58. 953-8.

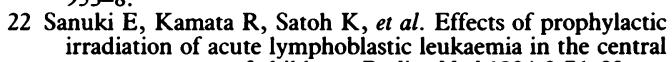
nervous system of children. Radiat Med 1984;2:76-83.

23 Stuss DT, Benson DF. Neuropsychological studies of the frontal lobes. Psychol Bull 1984;95:3-28.

24 Riccardi R, Brouwers P, Di Chiro G, Poplack DG. Abnorma computed tomography scans in children with acute ymphoblastic leukemia: serial long term follow-up. $f \mathrm{Clin}$ Oncol 1985;3:12-8.

25 Stoch MB, Smythe PM. Does undernutrition during infancy inhibit brain growth and subsequent intellectual development? Arch Dis Child 1963;38:546-52.

26 Cordano A, Baertl JM, Graham GG. Growth sequences during recovery from infantile malnutrition. $\mathcal{J}$ Pediatr 1963;63:698.

27 Williams JM, Davis KS. Central nervous system prophylatic treatment for childhood leukaemia: neuropsychological outcome studies. Cancer Treat Rev 1986;13:113-27. 